\title{
Correction to: A complex mechanism for HDGF-mediated cell growth, migration, invasion, and TMZ chemosensitivity in glioma
}

\author{
Ye Song ${ }^{1,2}$. Zheng Hu ${ }^{1} \cdot$ Hao Long ${ }^{1}$ - Yuping Peng ${ }^{1} \cdot$ Xi'an Zhang $^{1} \cdot$ Tianshi Que ${ }^{1}$. Shihao Zheng ${ }^{1} \cdot$ Zhiyong Li $^{1}$.

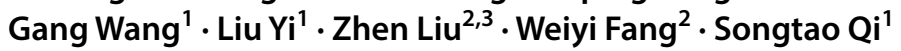

Published online: 8 October 2020

(c) Springer Science+Business Media, LLC, part of Springer Nature 2020

\section{Correction to: \\ Journal of Neuro-Oncology (2014) 119:285-295 \\ https://doi.org/10.1007/s11060-014-1512-4}

In the original publication, there are errors in Fig. 3D and Fig. 5C and they are corrected as shown below.
These errors do not affect the findings or conclusions of the article. The authors apologize for any inconvenience caused.

The original article can be found online at https://doi.org/10.1007/ s11060-014-1512-4.

Zhen Liu

narcissus_jane@163.com

$\triangle$ Weiyi Fang

fangweiyi1975@163.com

$\triangle$ Songtao Qi

qisongtaosjwk@163.com

1 Department of Neurosurgery, Nanfang Hospital,

Southern Medical University, Guangzhou, Guangdong,

People's Republic of China

2 Cancer Research Institute of Southern Medical University, Guangzhou, Guangdong, People's Republic of China

3 Department of Pathology, Basic School of Guangzhou Medical College, Guangzhou, Guangdong,

People's Republic of China 
A
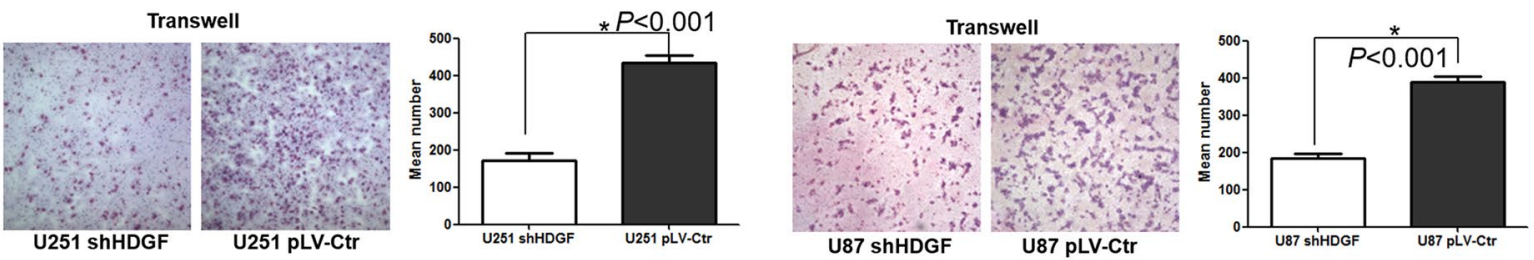

B
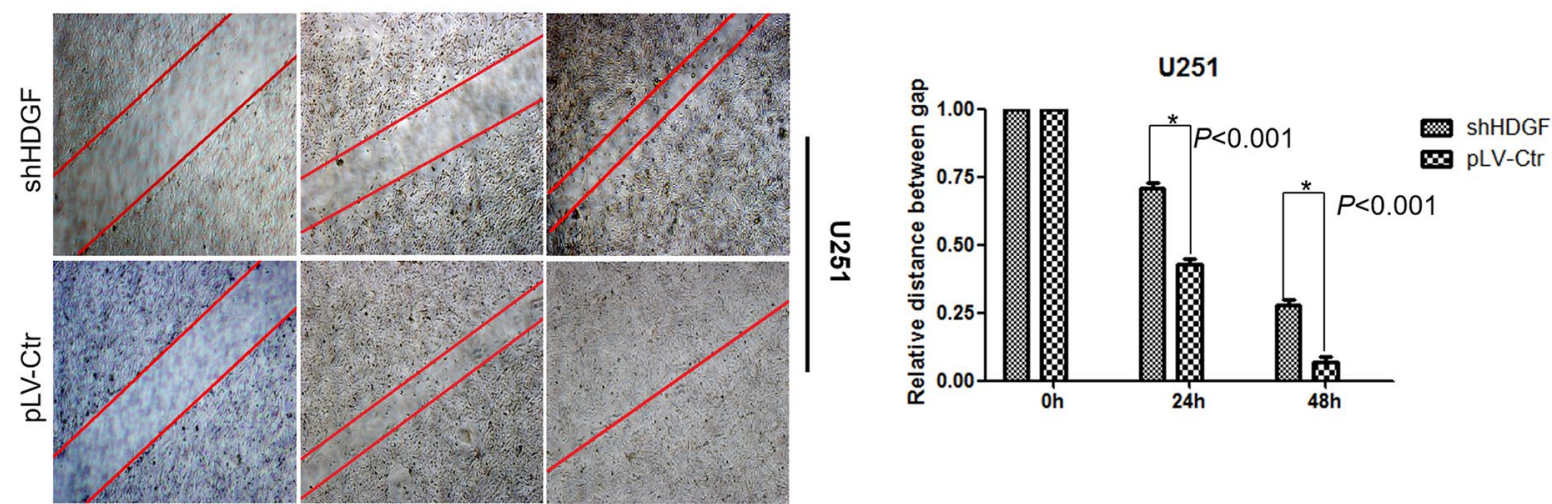

\section{灾}

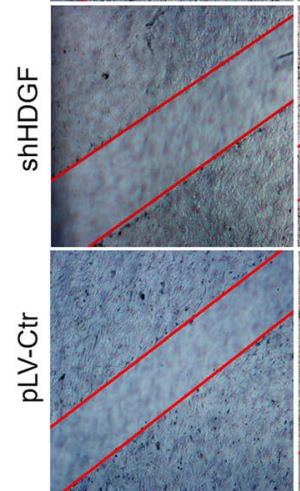

$\mathrm{Oh}$

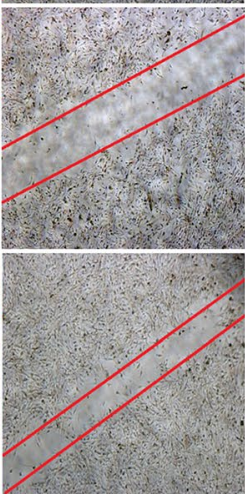

$24 \mathrm{~h}$

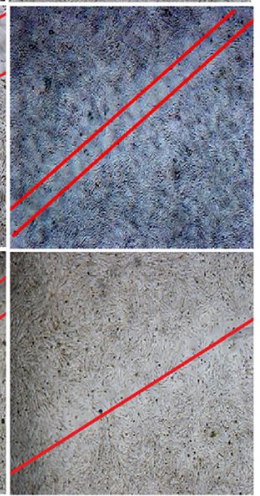

$48 h$

C
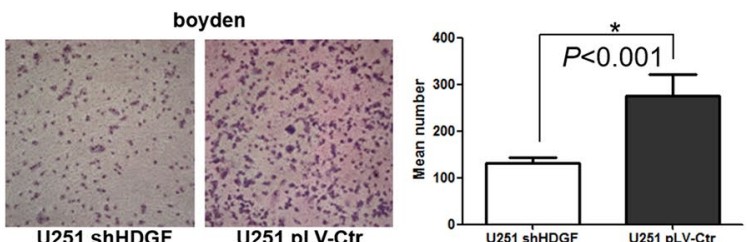

D
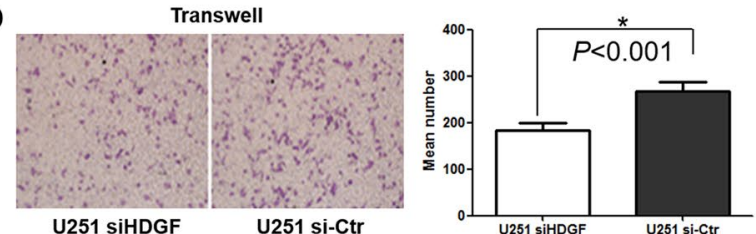

E
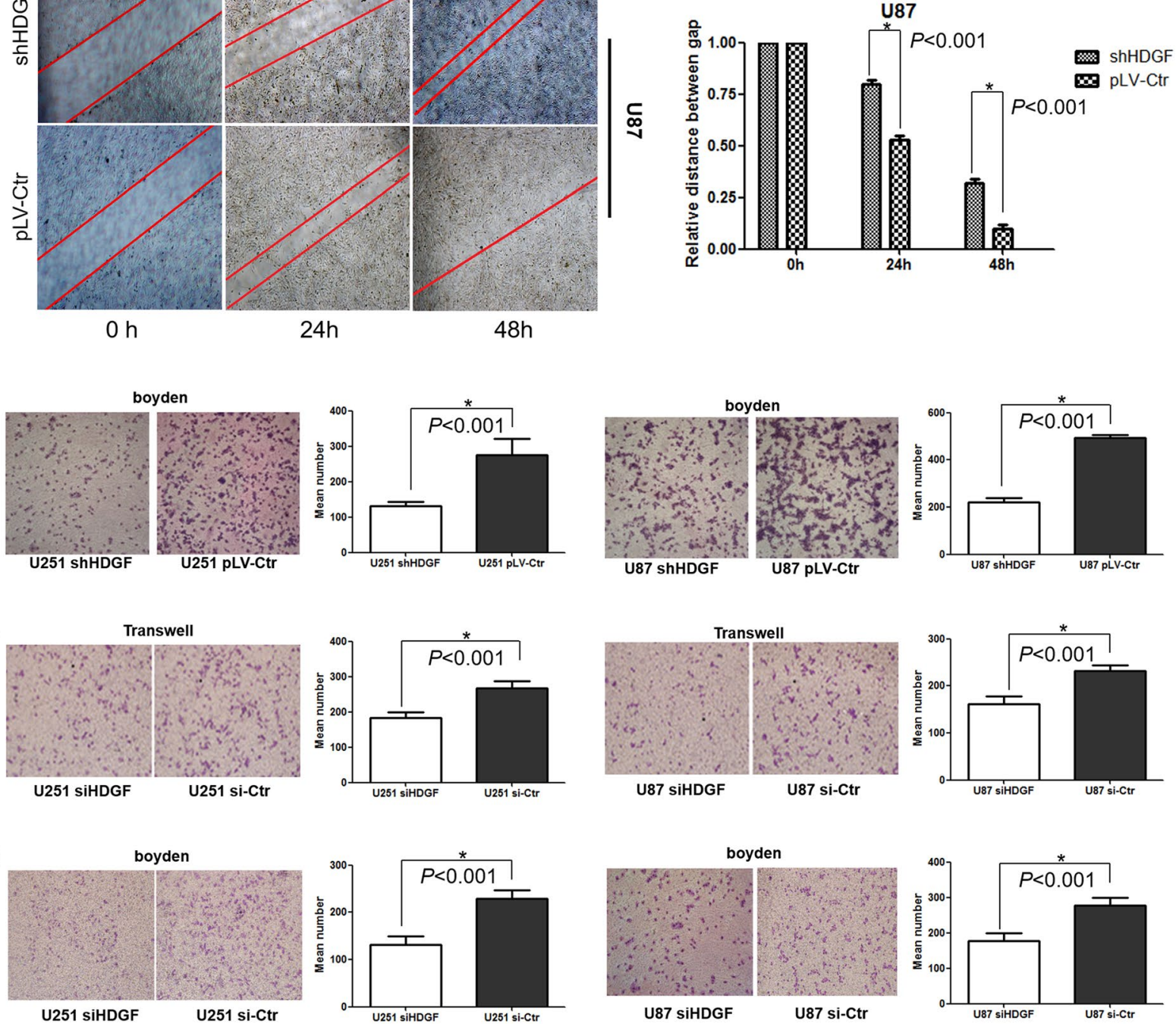
४Fig. 3 HDGF expression knockdown decreases cell migration and invasion. The U251 si-Ctr panel in Fig. 3e is replaced with an appropriate graph 

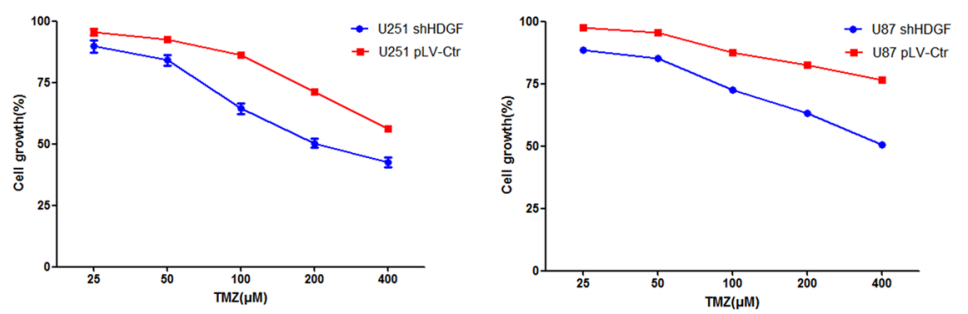

C
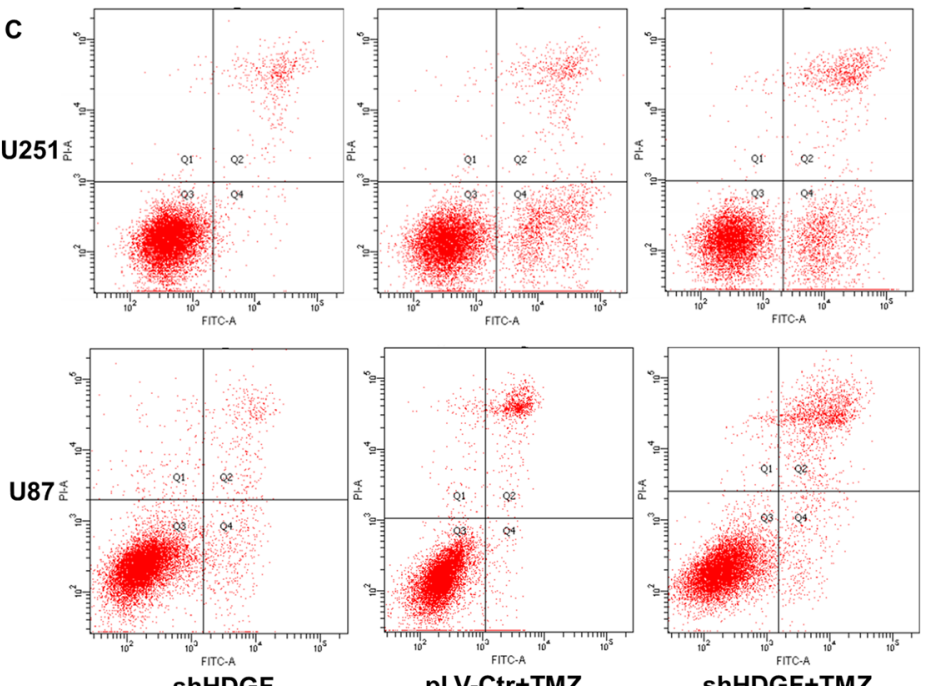

shHDGF+TMZ
B

\begin{tabular}{ccc}
\hline Cell lines & $\mathrm{TMZ} \mathrm{IC}_{50}(\mu \mathrm{M})$ & $\mathrm{SD}$ \\
\hline U251-Ctr & 487.3 & 5.8 \\
U251 shHDGF & 202.5 & 7.3 \\
U87-Ctr & 808.4 & 11.2 \\
U87 shHDGF & 406.3 & 9.4 \\
\hline
\end{tabular}
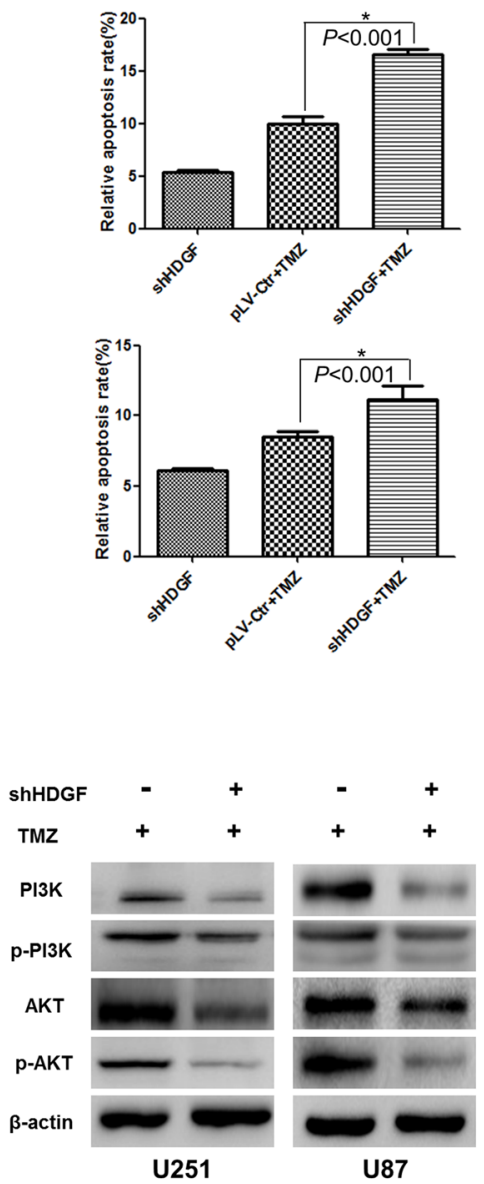

Fig. 5 HDGF downregulation enhances TMZ-induced cytotoxicity and apoptosis in glioma cells. The U87 pLV-Ctr+TMZ panel in Fig. 5c is replaced with an appropriate graph

Publisher's Note Springer Nature remains neutral with regard to jurisdictional claims in published maps and institutional affiliations. 